\title{
A FORTUNA CRÍTICA DE THOMAS MANN NO BRASIL: CARPEAUX E ROSENFELD
}

Gustavo Ramos de Souza*

RESUMO: Considerando a importância da descendência materna brasileira na obra do escritor alemão Thomas Mann, este ensaio tem como objetivo observar de que maneira dois críticos e ensaístas radicados no Brasil compreenderam a obra manniana: Anatol Rosenfeld e Otto Maria Carpeaux. Serão analisados dois ensaios de Rosenfeld da coletânea Thomas Mann, publicado em 1994 pela Editora Perspectiva, sob supervisão de Jacó Guinsburg, além de três textos de Carpeaux sobre o escritor extraídos de Ensaios reunidos: 1942-1978, organizado por Olavo de Carvalho em 1999 História da literatura ocidental: VI, de 1964, e A literatura ale$m a ̃$ também de 1964. A intenção é apontar as semelhanças e dessemelhanças apresentadas pelos dois críticos acerca da obra de Thomas Mann.

PALAVRAS-CHAVE: Thomas Mann; Crítica; Anatol Rosenfeld Otto Maria Carpeaux.

\section{*avulsoaoavesso@gmail.com \\ Doutorando e Mestre em Estudos Literários, pela \\ Universidade Estadual de Londrina.}

ABSTRACT: Considering the importance of the Brazilian maternal progeny in the work of German writer Thomas Mann, this essay aims to note how two critics and essayists rooted in Brazil understood the Mannian work: Anatol Rosenfeld and Otto Maria Carpeaux. It will be analyzed two essays by Rosenfeld from the selection Thomas Mann, published in 1994 by Perspectiva, under the supervision of Jacó Guinsburg, besides three texts by Carpeaux about the writer from: Ensaios reunidos: 1942-1978, organized by Olavo de Carvalho in 1999, História da literatura ocidental: VI, from 1964, and $A$ literatura alemã, also 1964. The intention is to point out the similarities and dissimilarities shown by both critics about Thomas Mann's work.

KEYWORDS: Thomas Mann; Criticism; Anatol Rosenfeld; Otto Maria Carpeaux. 


\section{INTRODUÇÃO}

Propor discutir a obra de Thomas Mann, a partir de sua fortuna crítica, na visão de dois dos seus principais comentadores no Brasil, Otto Maria Carpeaux e Anatol Rosenfeld, parece, à primeira vista, um exercício aleatório. Todavia quer seja pela importância dos dois críticos dentro dos estudos literários brasileiros a partir dos anos 1940, quer seja porque ambos, ainda que por razões diversas, são referências obrigatórias quando se analisa a obra manniana, tal aproximação se revela menos gratuita e oferece alguns pontos em comum - mesmo porque é também a partir da década de 1940 que se intensificam as traduções das principais obras de Mann no país, sobretudo pela editora Globo. Ressalta-se, no entanto, que Carpeaux enxergava a obra de Mann com reservas, ao passo que Rosenfeld nutria especial afeição pelo romancista alemão: é aí que reside nosso interesse.

Embora Thomas Mann seja cada vez mais estudado em terras brasileiras, talvez um dos estudos mais significativos sobre sua obra seja a dissertação de mestrado de Claudia Sybille Dornsbuch, defendida em 1992, na USP, e intitulada Aspectos interculturais da recepção de Thomas Mann no Brasil, porquanto busca compreender a sua obra a partir de resenhas publicadas em jornais brasileiros entre 1937 e 1990 A autora detém-se, porém, nas dificuldades encontradas na compreensão do autor alemão devido às diferenças culturais entre os dois países. Assim, ao escolhermos dois críticos de origem próxima à de Mann, partimos do pressuposto que suas análises, em vez de recaírem em explanações sobre teoria da literatura ou em eventuais comparações com a literatura brasileira, buscariam avaliar a obra a partir de suas qualidades intrínsecas. Quer isso seja verdadeiro ou não, o método empregado aqui é diferente, pois, no lugar de resenhas, o corpus compõe-se de textos editados em formato de livro. Assim, no caso de Rosenfeld, os ensaios que serão analisados encontram-se na coletânea Thomas Mann, publicado em 1994 pela Editora Perspectiva, sob supervisão de Jacó Guinsburg. Quanto aos textos de Carpeaux, embora constituam um volume menor que o de Rosenfeld, encontram-se em três livros: Ensaios reunidos: 1942-1978, organizado por Olavo de Carvalho em 1999, História da literatura ocidental: VI, de 1964, e A literatura alemã, também de 1964. Enfim, busca-se apontar as semelhanças e dessemelhanças apresentadas pelos dois críticos acerca da obra manniana.

\section{OTTO MARIA CARPEAUX}

Há três textos em que Carpeaux comenta a obra de Thomas Mann: “Admirável Thomas Mann”, publicado em 1942 e coligido em Ensaios reunidos; sendo que os outros dois foram publicados em 1964, fazendo parte de historiografias: História da literatura ocidental: VI e A literatura alemã. O que salta aos olhos na leitura dos três textos é a diferença de perspectiva adotada pelo crítico entre 1942 e 1964, quer dizer,
EM TESE
BELO HORIZONTE
v. 21
N. 1
JAN.-ABR. 2015
SOUZA. A fortuna crítica de Thomas Mann No Brasil [...]
P. $116-129$

\section{Crítica Literária, outras Artes e Midias}


1. CARPEAUX. "Admirável Thomas Mann", p. 251.

2. CARPEAUX. "Admirável Thomas Mann", p. 251 decorridos mais de 20 anos, o seu posicionamento frente à obra do romancista alemão sofre uma profunda mudança. Vale lembrar que Thomas Mann só morreria em 1955, tendo publicado entre o ano do primeiro ensaio de Carpeaux e sua morte pelo menos três obras importantes: Doutor Fausto (1947), O Eleito (1951) e As confissões de Felix Krull (1954), embora este tenha sido iniciado em 1922 e publicado inacabado. Mencionar esses dados é importante porque acreditamos que a reviravolta crítica de Carpeaux deve-se, sobretudo, à publicação de Doutor Fausto. Aliás, após a publicação desse romance, aquilo que o crítico antes via como defeito anteriormente passa a ser virtude, além de enxergar características que então acreditava estar ausentes de sua obra

"Admirável Thomas Mann" é, sem dúvida, uma das maiores diatribes contra a obra do autor de A Montanha Mágica. $\mathrm{O}$ crítico inicia o seu ensaio afirmando que é praticamente impossível não admirar Mann, visto se tratar de uma unanimidade: "Todos o leem, e todos o admiram, do crítico mais exigente até à girl mais engraçada”. ${ }^{1}$ Porém, fazendo ecoar avant la lettre Nelson Rodrigues, para quem toda unanimidade é burra, afirma que "a admiração é a inimiga mortal da compreensão; sobretudo a admiração unânime, indiscutida”. ${ }^{2}$ Logo, a tarefa a que se propõe é desmistificar o mito Thomas Mann, a fim de compreender os riscos de elevá-lo a um pedestal. Carpeaux, no entanto, sabe dos perigos de sua empreitada, porquanto a literatura universal é repleta de exemplos em que a análise destruidora de um autor revela tão somente incompreensão do crítico, na medida em que, havendo realmente valor na obra, a crítica reduz-se a "montões de papel de embrulho, papel sujo". ${ }^{3}$ A despeito disso, pretende desnudar o véu da admiração e revelar o verdadeiro Mann:

Que é que a gente admira em Thomas Mann? O pensador, o escritor, o alemão. Dizem-no um pensador profundo, um escritor de primeira ordem, e a encarnação de tudo o que é ou foi honesto e admirável no homem alemão. Na verdade, Thomas Mann é um pensador confuso, é o maior dos escritores de segunda ordem, e a alemanidade não é a essência do seu ser, mas o amor infeliz dum bastante fraco herói de tragédia. ${ }^{4}$

A provocação não se detém aí. O crítico põe-se a pontuar os motivos por que acredita ser Thomas Mann um pensador confuso, um escritor de segunda ordem e a encarnação trágica da alemanidade. Quanto ao primeiro aspecto, diz não haver um só pensamento original, pois o autor debate-se entre as ideias de Nietzsche, Schopenhauer e Wagner: "De Schopenhauer, Mann tem a expressão filosófica da decadência; de Nietzsche, a diagnose e a explicação da decadência; em Wagner procura a superação da decadência pelas ilusões intencionais dum romantismo ébrio". ${ }^{5}$ Ora, ainda que exista no jovem Mann - em Os Buddenbrooks (1901), Tonio Kroeger
3. CARPEAUX. "Admirável Thomas Mann", p. 252.

4. CARPEAUX. "Admirável Thomas
5. CARPEAUX. "Admirável Thomas Mann', p. 252.

\section{Crítica Literária, outras Artes e Midias}


(1903) e A Morte em Veneza (1912) - um certo fascínio pela decadência, não se trata de empréstimo schopenhauriano, mas antes do zeitgeist das artes naquele momento. Negar que o decadentismo e a doutrina da "arte pela arte" são um reflexo da metafísica das artes de Schopenhauer seria incorrer em equívoco, mas Mann em nenhum momento renega a lógica da sociedade burguesa, que condena o artista ao papel de consciência infeliz. No tocante à sua dívida Nietzsche, trata-se antes da antítese dialética ao pessimismo de Schopenhauer do que a diagnose dessa decadência Grosso modo, é sabido que Schopenhauer propõe que o homem deve buscar um quietivo à Vontade (cega e irracional), seja na contemplação artística, seja adotando a postura ascética; a contrario, Nietzsche, pelo menos em sua grande obra de juventude, $O$ Nascimento da Tragédia, afirma que é necessário afirmar o dionisíaco, o irracional. Assim, não se trata meramente de expressão e explicação da decadência, mas uma dialética que busca conciliar vida e espírito - motivo que atravessa toda a obra de Mann. Em relação ao romantismo ébrio wagneriano, este se configura muito mais no êxtase dionisíaco propiciado pelo espírito da música do que propriamente pela superação da decadência em ilusões. Ademais, se Wagner está presente em sua obra, deve-se ao fato de Mann ser melômano e dedicar-lhe homenagem; e não por contribuições filosóficas.
Quanto à segunda censura, a de ser um escritor de segunda ordem, Carpeaux não está acrescentando nada de novo às críticas feitas a Mann, porquanto, subjacente a esse discurso coloca-se a eterna querela entre vanguarda e realismo crítico, segundo a qual os escritores realistas estariam fazendo literatura como os mestres do século XIX (Tolstói, Henry James e Gustave Flaubert), em vez de trazer inovações técnicas, como André Gide, Franz Kafka, James Joyce, William Faulkner, entre outros. O realismo faria parte, portanto, do segundo escalão da literatura, e Mann seria o maior entre os escritores de segunda ordem. Por fim, quanto à alemanidade $^{6}$, Carpeaux esquece-se de que a sua essência é hegeliana (idealista) e não schopenhauriana (a-metafísica). Assim, quando diz que Mann é um fraco herói trágico, para acusar o seu caráter alemão, não leva em conta que a evolução da obra manniana, de Os Buddenbrooks até a tetralogia José e seus irmãos, aponta para a superação da alemanidade, do romantismo, do idealismo responsável pela tragédia alemã na Segunda Guerra.

Mas pontuemos outras críticas feitas por Carpeaux: "Não sendo pensador original ou claro, Mann é um grande manejador de pensamentos, o que é a primeira condição do ensaísta"? Com isso, o crítico pretende dizer que os seus romances não são romances stricto sensu, mas sim ensaios, ou melhor, ensaios fracassados que se tornaram romances. Em suas palavras: "Os
6. Nietzsche trata do problema da alemanidade em diversas de suas
obras, entre as quais: Ecce homo, em que, no capítulo intitulado "Por que sou tão inteligente", afirma: "o clima alemão basta por si mesmo para enfraquecer as vísceras fortes e até predispostas ao heroísmo [...]. A partir das consequências deste 'idealismo', explico todos os erros, todos os grandes desvios do instinto" (NIETZSCHE, 2008, p. 28-29). Idealismo, como afirmação da interioridade, recusa da realidade concreta e crença no progresso do espírito, é o que caracteriza do espirito, e o que caracteriza equívoco de Carpeaux está em atribuir essa alemanidad fracassada a Thomas Mann ao mesmo ta a Thomas Mann, ao sua influência schopenhauriana sua ina é anti-hegeliana. Assim a qual e anti-hegeliana. Assim como Nietzsche, Mann busca alemãs de seu espírito.

7. CARPEAUX. "Admirável Thomas Mann", p. 252.
EM TESE $\quad$ BELO HORIZONTE $\quad$ v. $21 \quad$ N. $1 \quad$ JAN.-ABR. $2015 \quad$ SOUZA. A fortuna crítica de Thomas Mann No Brasil [...] $\quad$ P. 116-129

\section{Crítica Literária, outras Artes e Mídias}


8. CARPEAUX. "Admirável Thomas Mann", p. 253.

9. CARPEAUX. "Admirável Thomas Mann", p. 253.

10. CARPEAUX. “Admirável Thomas Mann", p. 254 grandes romances são caducos; não passam, afinal, de imensos ensaios gorados de grande ensaísta das pequenas formas”. ${ }^{.}$ Dizer que os romances são pretextos para a discussão de ideias significa que são pobres quanto à fábula, ou seja, Mann não saberia narrar histórias; estas apenas ilustrariam as suas ideias emprestadas. Carpeaux continua: "Thomas Mann é muito pobre de imaginação. Em compensação, sabe compor como um músico, fazendo mil variações engenhosas em torno de um tema monótono". ${ }^{9}$ Com efeito, essa crítica é válida até certo ponto, porquanto, desde Tonio Kroeger até Doutor Fausto, as obras de Mann são desdobramentos em cima de um motivo que já aparece em seu primeiro romance, Os Buddenbrooks, a saber: a antítese entre espírito e vida, artista e burguês. No tocante ao estilo manniano, marcado pelo frequente uso de leitmotivs, o crítico escreve:

Thomas Mann é um grande estilista, na significação menos boa da palavra; ele estiliza tudo e ao seu estilo também. Estilista de primeira ordem, com as virtudes estilísticas da época burguesa: irônico, espirituoso, sentimental, psicológico, analítico. Um Nietzsche disfarçado em Flaubert. Grande nunca, sempre correto; correção laboriosa, penosa, estilizada à maneira do Goethe da velhice. ${ }^{10}$

Quanto à escrita ao modo do velho Goethe, o próprio Thomas Mann chega a se questionar a respeito de seu estilo, quando comparado aos escritores de vanguarda: "Meu preconceito era que, comparada ao vanguardismo excêntrico de James Joyce, minha obra parecesse de um tradicionalismo insosso" ${ }^{11}$ Por mais que o seu realismo não fosse transgressor no plano formal, Mann é continuador de uma tradição romanesca que remonta a Balzac. Ademais, ele reinventa o bildungsroman em A montanha mágica, ao fazer de herói um engenheiro simplório, quando a regra era explorar as potencialidades de indivíduos excepcionais, como é caso de Wilhelm Meister no romance de Goethe. Já a ironia, ainda que estilizada, está longe de ser um defeito. Em Mann, ela surge justamente do descompasso entre a forma elevada e o conteúdo trivial; afinal, ironia é distância - parafraseando o romancista. O deslocamento da obra manniana no quadro das vanguardas, mais do que tradicionalismo ou apego aristocrático ao passado, pode ser interpretado também como ironia, na medida em que se torna paródia de uma forma em dissolução, decadente, tal como o mundo de suas personagens.

A última acusação que Carpeaux faz a Mann é a ausência de dialética: "Por falta de dialética, Mann não compreende bem a decadência da burguesia, a sua evolução - da aristocracia de espírito de 1830 à aristocracia de dinheiro de 1900 - evolução que é assunto de Os Buddenbrooks". ${ }^{12}$ Ainda que não siga a tradição hegeliana, Mann elabora uma dialética
11. MANN. A Gênese do Doutor Fausto: romance sobre um romance, p. 75.

12. CARPEAUX. "Admirável Thomas Mann", p. 255.
EM TESE
BELO HORIZONTE
v. 21
N. 1
JAN.-ABR. 2015
SOUZA. A fortuna crítica de Thomas Mann No Brasil [ ...]
P. $116-129$

\section{Crítica Literária, outras Artes e Mídias}


13. MANN. Tonio Kroeger/ A morte em Veneza, p. 84

14. CARPEAUX. "Admirável Thomas Mann", p. 257. sui generis, quando, por exemplo, confronta Schopenhauer e Nietzsche. Em relação a'Os Buddenbrooks, existe uma tensão dialética entre forma e conteúdo, i.e., entre o realismo burguês e a dissolução dos valores da burguesia tradicional - justamente o seu tema. Dialético é também o fato de a evolução espiritual significar a degenerescência fisiológica do clã dos Buddenbrook, sendo que o ponto de tensão fica concentrado em Thomas, o herói do romance. Em Tonio Kroeger, esse jogo dialético fica ainda mais evidente: "Estou entre dois mundos; não me sinto à vontade em nenhum dos dois e por isso tenho um pouco de dificuldade. Vocês, artistas, me chamam de burguês, e os burgueses sentem-se tentados a prender-me... não sei qual dos dois me magoa mais". ${ }^{13} \mathrm{O}$ artista figura, portanto, como um outsider, como a consciência infeliz de uma época de decadência.

Por fim, é espantosa a incompreensão vinda de um crítico tão arguto, como quando comenta a efemeridade da obra de Mann: "Toda a sua literatura anterior passou, desde já, à categoria dos romances que 'tida a gente precisa ter lido', durante uma estação, para desaparecerem depois nas estantes" ${ }^{14}$ Quanto a esse juízo precipitado, a história vem demonstrando o quão estava errado, visto que quase sessenta anos se passaram desde a sua morte, mas sua obra tem sido cada vez mais lida e estudada. Com efeito, se fosse depender de ensaios como “Admirável Thomas Mann”, a obra de

\begin{tabular}{|c|c|c|c|c|c|c|}
\hline EM TESE & BELO HORIZONTE & v. 21 & N. 1 & JAN.-ABR. 2015 & SOUZA. A fortuna crítica de Thomas Mann No Brasil [...] & P. 116-129 \\
\hline
\end{tabular}

Carpeaux também ficaria acumulando poeira e traças nas estantes - o que, felizmente, não é caso.

Contudo, passados mais de vinte anos, Carpeaux volta a falar de Thomas Mann, ainda que não pormenorizadamente. Em A literatura alemã, Mann, que até então escrevia ensaios fracassados em forma de romance, passa a ser considerado o clássico do gênero romance. Para Carpeaux,

Os grandes romances de Goethe, Stifter, Keller não são romances no sentido da tradição ocidental. No passado, só há Fontane. Só este e Thomas Mann podem figurar ao lado de Balzac, Stendhal e Flaubert, Hardy, Henry James e Conrad, Pérez Galdós e Verga. Com isso está determinada sua categoria universal. ${ }^{15}$

Quanto ao estilo, visto então como vício, Carpeaux reafirma dívida manniana para com Goethe, por causa de sua escrita cheia de "subentendidos, alusões, insinuações; tudo isso vivificado por um elemento totalmente novo na literatura alemã: a ironia, que serve para abrir perspectivas ou para abrandar a emoção profunda, inconfundivelmente romântica, de outros trechos". ${ }^{16}$ Nesse sentido, Mann seria simultaneamente alemão e universal, clássico e romântico, sendo que a ironia torna-se a mediadora dessa tensão. Deduz-se, portanto, um forte sentimento de dialética em sua literatura, a qual se reflete na tentativa de preservar uma forma em decadência. Segundo Carpeaux, "a superfície (ou pose)
15. CARPEAUX A Literatura Alemã p. 191.

16. CARPEAUX. A Literatura Alemã p. 191.

\section{Crítica Literária, outras Artes e Mídias}


17. CARPEAUX. A Literatura Alemã, p. 191

18. CARPEAUX. A Literatura Alemã p. 192. goethiana esconde o processo dialético de decomposição do Romantismo pela ironia e de restabelecimento da emoção pelo humorismo doloroso". ${ }^{17}$ Não se trata simplesmente da típica ironia romântica, visto que não ocorre o questionamento da forma a partir da metalinguagem gerando distanciamento; antes, a ironia de Mann é erótica, pois, ao mesmo tempo que se coloca-se à distância para questionar princípios opostos, busca conciliá-los em sua negatividade, posto que sejam manifestações de uma unidade profunda.

É interessante observar a reviravolta de Carpeaux no que diz respeito à presença de dialética em Mann, pois no ensaio de 1942 afirmava que, na obrado autor de Os Buddenbrooks, não existia dialética, devido ao fato de desconhecer Hegel. Agora, porém, o romance é ao mesmo tempo a derrocada de uma família alemã e da burguesia europeia, estando repleto de tensões:

Outros problemas, outras dialéticas escondidas nesse romance logo se revelaram porque Mann insistiu nelas: a oposição entre o artista e o burguês e a doença fatal do burguês que se torna artista - problema pré-formado em Flaubert; e a relação entre a arte do artista e a doença do artista - problema pré-formado em Nietzsche. A expressão meio romântica, meio humorística dessa dialética é a novela Tonio Kroeger. não é a obra-prima absoluta de Mann, mas a chave para a compreensão de todas as outras. ${ }^{1}$
Apenas com A Montanha Mágica é que se tornaria mais clara essa dialética, porquanto se manifesta no plano das ideias: "Mas a dialética manifesta-se agora em grandes discussões ideológicas, de modo que longos trechos do romance são verdadeiros ensaios sobre os problemas da civilização e mais um elemento novo - da política europeia” ${ }^{19} \mathrm{Com}$ efeito, esse romance é considerado um ponto de inflexão na obra de Mann, na medida em que abandona a sua postura apolítica e extremamente nacionalista expressa em Considerações de um apolítico (1918) e alerta sobre as consequências do não-engajamento. A certa altura do romance, é dito: "Não existe a não-política. Tudo é política" ${ }^{20}$ Isso significa que, ao se negar um posicionamento, corre-se o risco de contribuir indiretamente para a instalação de forças reacionárias no poder, como foi o caso da República de Weimar. Mais do que ninguém, Mann sabe dos perigos em permanecer morno diante de situações políticas instáveis. É nessa direção que se deve considerar A Montanha Mágica como o seu mea culpa.

Carpeaux, no capítulo em que trata da literatura da "época do desequilíbrio europeu”, em História da Literatura Ocidental, aponta essa decisiva tomada de posição de Mann:

Através do ceticismo do Zauberberg ( A Montanha Mágica), reflexo das vacilações espirituais do após-guerra e panorama da decadência europeia generalizada, o antigo nacionalista ale-
19. CARPEAUX. A Literatura Alemã, p. 192.

20. MANN. A Montanha Mágica, $\mathrm{p}$ 686.

EM TESE $\quad$ BELO HORIZONTE $\quad$ v. $21 \quad$ N. $1 \quad$ JAN.-ABr. $2015 \quad$ SOUZA. A fortuna crítica de Thomas Mann No Brasil [...] $\quad$ P. 116-129

\section{Crítica Literária, outras Artes e Mídias}


21. CARPEAUX. História da Literatura Ocidental: VI, p. 2817.

22. CARPEAUX. História da Literatura Ocidental: VI, p. 2818- mão chegou a transformar-se em "bom europeu" no sentido de Nietzsche, desempenhando esse papel, com maior coragem, contra o nacionalismo da Alemanha rebarbarizada. ${ }^{21}$

Observa-se que, embora tenha sido provavelmente Doutor Fausto que mudou a perspectiva de Carpeaux, o crítico reavalia também a importância de A Montanha Mágica, vista então como uma pessimista epopeia da doença que não apontava soluções. Tanto que se passa a rebater as críticas que ele mesmo censurava no passado: de ordem política, pois antes de 1918, Mann foi atacado pelos liberais e esquerdistas de nacionalista, luterano ortodoxo e ultraconservador na glorificação romântica da decadência. Depois de 1918 passou a ser considerado um "vendido" à democracia ocidental e traidor do nacionalismo. Para Carpeaux, essa polêmica não é nenhum demérito, pois demonstra que Mann foi o primeiro romancista alemão a colocar o problema político no centro de sua obra. Quanto às críticas de ordem estética, são aquelas dos críticos de vanguarda, que "censuraram o tradicionalismo de Mann, continuando a escrever, em 1940 romances no mesmo estilo goethiano-tolstoiano de antes das grandes guerras: num estilo em que apenas apreciavam a fina ironia". ${ }^{22}$ Carpeaux termina o seu texto comentando sobre Doutor Fausto, romance que desmentiria todas as críticas feitas a Mann:
No seu romance épico Doktor Faustus, a carreira artística do grande compositor Leverkuehn coincide com a história política da Alemanha durante os últimos decênios: os dois grandes temas, a política e a música, estão ligados através de uma nova técnica novelística na qual "tudo alude a tudo": tudo é realidade e tudo é símbolo; e um fato real de dimensão simbólica, a tentação da Alemanha e do artista pelo demônio, dá à obra a dimensão metafísica e transcendental. O estilo é, outra vez, complexo à maneira do estilo de Goethe, mas iluminado por todas as luzes da ironia. ${ }^{23}$

\section{ANATOL ROSENFELD}

A coletânea Thomas Mann compõe-se de quatorze ensaios. Optamos por comentar aqueles que analisam a obra manniana adotando um caráter mais genérico; por isso, abstemo-nos de falar sobre os ensaios que tratam da sua correspondência, temas específicos ou obras particulares. Logo, os ensaios que integram o corpus são os dois primeiros do volume organizado por Jacó Guinsburg: “Thomas Mann” (1952) e "Um esteta implacável” (1946-1949).

Quanto ao primeiro, apesar da curta extensão, confere um resumo bem detalhado sobre o autor e lança ideias que podem ser aprofundadas por quem se dedicar a estudá-lo. A ideia central do ensaio gira em torno de um fato biográfico e como isso se reflete na obra de Mann: descendência materna de uma brasileira,
23. CARPEAUX. História da Literatura Ocidental: VI, p. 2819
EM TESE
BELO HORIZONTE
v. 21
N. 1
JAN.-ABR. 2015
SOUZA. A fortuna crítica de Thomas Mann № Brasil [ ...]
P. $116-129$

Crítica Literária, outras Artes e Mídias 
24. ROSENFELD. Thomas Mann, $\mathrm{p}$. 20-21.
Júlia da Silva Bruhns. De fato, é este o assunto de Tonio Kroeger, novela em que o protagonista é um artista mestiço que se sente deslocado no lugar em que vive. Nas palavras de Rosenfeld,

Muito cedo Thomas se convenceu da sua missão de escritor e artista. Tendo a clara intuição da sua situação anormal de artista dentro da sociedade burguesa, teve a sensibilidade para esse fato enormemente aguçada pela anormalidade da sua ascendência entre as famílias tradicionais da sua cidade natal. ${ }^{24}$

A hipótese de que parte Rosenfeld consiste em demonstrar como um fato pessoal e interior caminha lado a lado com o próprio mecanismo da sociedade burguesa, quer dizer, o não sentir-se normal deve-se tanto à condição mestiça, como também à condição de artista - o assinalado, o maldito, o desajustado num mundo que preza muito mais pelos assuntos materiais do que pelos espirituais. Trata-se, em certa medida, da alienação hegeliana, embora não decorra da objetivação, mas de sua impossibilidade. Rosenfeld continua:

Pois aquele incidente biográfico sem grande importância intrínseca na realidade, o tema fundamental da sua obra, toda ela dedicada, em essência, à análise constante e infinitamente variada daquilo que nós poderíamos chamar com uma expressão de Hegel, mais tarde também empregada por Marx, de "alienação", conquanto a acepção do termo neste nosso caso seja um tanto modificada. Separação, anormalidade, isolação, marginalidade, alienação da média secular - eis a experiência pungente do jovem Mann, experiência que encontra cedo expressão em pequenos contos e novelas e no romance Os Buddenbrooks.

A alienação coincide com o aumento da espiritualização, mas também com a decadência biológica em Os Buddenbrooks. Na dialética do jovem Mann, não existe conciliação possível entre vida e espírito; por isso, em A Morte em Veneza, quando o escritor Aschenbach abre mão da esterilidade do espírito e parte em busca do conhecimento sensual, à maneira do Fausto goethiano, só encontra degradação moral e morte. Em Tonio Kroeger, o artista torna-se uma espécie de eremita da vida moderna e urbana, pois lhe é impossível ajustar-se entre os "normais" de cabelos loiros e olhos azuis, a quem de resto vê com certo desdém. A experiência do jovem Mann em relação ao mundo em que vive é de distância e, portanto, de ironia. Rosenfeld afirma que "distante da sua sociedade, como artista e marginal, ele vê a sociedade, que para ele se confunde com a burguesia, através do prisma da ironia. Distante, ao mesmo tempo, do puro intelectualismo por sentir-se demasiado burguês e artesão, ele ironiza também a posição do artista e do alienado". ${ }^{26}$

A dialética manniana, a despeito de não conseguir uma suprassunção (aufhebung), tem muito bem definidos os pólos
25. ROSENFELD. Thomas Mann, $\mathrm{p}$. 21.

26. ROSENFELD. Thomas Mann, $\mathrm{p}$
EM TESE
BELO HORIZONTE
v. 21
N. 1
JAN.-ABR. 2015
SOUZA. A fortuna crítica de Thomas Mann No Brasil [...]
P. $116-129$

\section{Crítica Literária, outras Artes e Midias}


27. ROSENFELD. Thomas Mann, $\mathrm{p}$. 22-23.

28. ROSENFELD. Thomas Mann, $\mathrm{p}$. 23. que a compõem. De um lado, a sociedade, o senso comum, a ordre du jour, o trabalho, a vida; de outro, o individualismo, o escapismo romântico, a contemplação, o espírito, a embriaguez da música, a dissolução. ${ }^{27}$ Tanto de um lado quanto do outro existem riscos, visto que, não havendo equilíbrio entre vida e espírito, pode-se pender para um dos lados. Vida em excesso, no sentido de um transbordamento dionisíaco, significa morte; espírito em excesso conduz ao quietismo contemplativo e, por conseguinte, à doença e à morte. De acordo com Rosenfeld,

Toda a vida de Thomas Mann, no seu sentido mais profundo, é um constante esforço de superar a sua natureza, impregnado do romantismo musical da Alemanha [...]. E toda a sua obra nada é senão a expressão estética desse esforço constante de contrapor os dois valores, de pô-los em xeque, de referi-los num jogo de dialética altamente ambígua, de ironizar-lhes a unilateralidade, de salientar a necessidade de sua síntese final num humanismo em que espírito e vida se interpenetrem e em que o indivíduo isolado se integre de novo na sociedade, enriquecido pela experiência da "doença", da "morte" e da alienação. ${ }^{28}$

O que busca atestar Rosenfeld é de que maneira aquele trivial incidente biográfico vai se desdobrando e ganhando dimensões míticas e metafísicas. Para ele, o drama de Thomas Mann é o drama da Alemanha, do século XX, da humanidade em todas as épocas. Em A Montanha Mágica, o tema inicial se amplia, na medida em que não se trata mais da alienação do artista, mas sim de toda uma sociedade doente. É também nesse romance gigantesco que ocorre uma tentativa de superação daquela tensão dialética, haja vista que surge uma tomada de decisão. Diz Rosenfeld: "A decisão de Thomas Mann, todavia, é a de que Hans Castorp, para realizar-se, para fechar o círculo da sua educação humanista, tem de voltar à planície. A vida revela-se o valor mais alto". ${ }^{29}$ No entanto, ainda que haja uma tomada de posição, trata-se de um gesto irônico. Quando Hans decide deixar o mundo das ideias, descendo da montanha em direção à planície, à vida, o mundo lá embaixo se lhe apresenta como um campo de morte, pois irrompeu a Primeira Guerra Mundial. Assim, enquanto no clássico romance de formação, como o Wilhelm Meister de Goethe, ao concluir a sua educação o indivíduo retorna à sociedade a fim de pô-la em prática; em $A$ Montanha Mágica, o herói depara-se com um mundo em ruínas. É por isso que Rosenfeld afirma ser o romance de Mann uma continuação irônica e paródica do livro de Goethe. Em suas palavras,

se Goethe disse aos românticos alemães do seu tempo: Não se afastem da sociedade; o lugar do intelectual não é em Pasárgada; integrem-se no coletivo - Thomas Mann parece perguntar, cento e vinte anos mais tarde ao seu venerado mestre: Integrar sim,
29. ROSENFELD. Thomas Mann, p.
EM TESE
BELO HORIZONTE
v. 21
N. 1
JAN.ABR. 2015
SOUZA. A fortuna crítica de Thomas Mann No Brasil [...]
P. 116-129

\section{Crítica Literária, outras Artes e Mídias}



30. ROSENFELD. Thomas Mann, p.

31. ROSENFELD. Thomas Mann, $\mathrm{p}$. 27.

32. ROSENFELD. Thomas Mann, p. 28.

33. ROSENFELD. Thomas Mann, $\mathrm{p}$. 29. mas em que sociedade? Nesta sociedade conflagrada por guerras, produtora em série de alienados? Nesta sociedade em decadência, fragmentada e anormal, que parece ser a pista de loucos? ${ }^{30}$

Rosenfeld conclui o ensaio comentando sobre Doutor Fausto, romance que leva às últimas consequências a experiência da alienação, já que a personagem principal enlouquece após firmar o pacto com o diabo e contrair a sífilis: “a trágica situação da arte e do artista - que representa na obra de Mann o homem essencialmente ameaçado - decorre do fato de que a própria sociedade enlouqueceu". ${ }^{31}$ Isso significa que o magro tema biográfico do isolamento nada mais é que "um processo que se repete através da história e se perde na sombra do mito". ${ }^{32}$ É justamente o que Thomas Mann faz em sua tetralogia José e seus irmãos, quando sonda nos primórdios da humanidade o movimento de integração do individual ao coletivo. Ele parece nos dizer que apenas no período anterior à história era possível conciliar a contradição entre espírito e vida, sendo que, depois da Queda estaríamos todos condenados. Todavia, para Rosenfeld, apesar de Mann ter sofrido na pele a culpa da não-participação na vida política de seu país, apesar de ter sofrido e vivido a sua obra e seu pensamento, o seu valor ético ultrapassa o seu valor estético, isto é, Mann é "o exemplo de um homem que conseguiu reconciliar em si espírito e vida". ${ }^{33}$
Por fim, em relação ao segundo ensaio, "Um esteta implacável”, o qual é dividido em três partes, Rosenfeld procura, primeiramente, situar Thomas Mann na tradição artística do século XIX, alinhando-o a Wagner, Tolstói, Balzac e Zola, no sentido de manter um certo ceticismo quanto à razão e ao progresso, enquanto se sente fascinado pela íntima união musical com a noite e a morte - temas caracteristicamente românticos. Para Rosenfeld, "a obra de Thomas Mann se nos revela como o triste canto do cisne do século passado e, com isto, da burguesia, cujos valores essenciais, os do humanismo, ele sem dúvida procura salvar, tanto mais quanto estes foram assumidos pela burguesia e traídos por sua forma desagregada, a Bourgeoisie". ${ }^{34}$

Assim como a forma-sonata era a mais típica expressão da racionalidade burguesa da música oitocentista, dissolvendo-se no atonalismo de Liszt e Wagner e, posteriormente, na música dodecafônica de Schoenberg, o romance, solidificado por Balzac, Stendhal e Flaubert no mesmo período, encontrou o mesmo processo de dissolução formal em James Joyce, Franz Kafka e Marcel Proust. Da mesma forma que a música de Mahler era a tentativa de preservação da música tradicional, enquanto lutava contra a crise das formas, os romances de Mann, presos ao realismo tradicional, representam essa mesma tentativa de conservação de uma época que não existe mais, no entanto, ciente de estar numa encruzilhada histórica: “Thomas Mann encontra-se no fim de uma época, e suas obras
34. ROSENFELD. Thomas Mann, $\mathrm{p}$

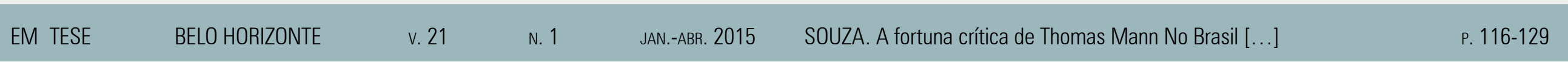

\section{Crítica Literária, outras Artes e Midias}


35. ROSENFELD. Thomas Mann, $\mathrm{p}$. 34.

36. ROSENFELD. Thomas Mann, $\mathrm{p}$. 37. são, em essência, variações sinfônicas deste processo lento e trágico de deterioração". ${ }^{35}$ É preciso, pois, levar em conta ao nos depararmos com sua obra que se trata da expressão artística de uma época de transição, o que lhe confere traços clássicos e ao mesmo tempo modernos, históricos e míticos.

Dando prosseguimento ao ensaio, Rosenfeld retoma os já conhecidos motivos da alienação e do incidente biográfico de Mann; entretanto, agora busca as raízes desse processo de alienação, que, segundo ele, estaria no advento da Renascença e da Reforma, com o surgimento da Modernidade. Ainda que, por um lado, isso tenha significado a libertação das amarras hierárquicas, por outro lado, tal libertação foi desprendendo paulatinamente o indivíduo do coletivo, relativizando todos os valores fixos e imutáveis, o que conduziu ao liberalismo, ao individualismo extremado e, paradoxalmente, ao totalitarismo, uma vez que este serve de religião substitutiva através de seus mitos pré-fabricados. ${ }^{36}$

Depois dessas considerações, Rosenfeld põe-se a identificar de que maneira isso se expressa na obra manniana, ao analisar Os Buddenbrooks, Tonio Kroeger, Sua alteza real, A morte em Veneza, Considerações de um apolítico, A Montanha Mágica, Doutor Fausto e José e seus irmãos. Em todas as suas análises, Rosenfeld aponta como a alienação, enquanto processo individual e coletivo, está presente tanto na forma quanto no conteúdo das obras. Mesmo as digressões filosóficas, que vão de Platão a Kierkegaard, passando por Kant, Schopenhauer e Nietzsche, mostram-se válidas em suas análises, na medida em que o próprio Thomas Mann dialogava constantemente com a tradição filosófica alemã.

Aliás, é em Doutor Fausto que observamos a raiz da tragédia do artista, da arte e da própria Alemanha. Ao fazer de Adrian Leverkühn estudante de Teologia e de Música, Mann retoma o espírito da Reforma, visto que Lutero apontava o parentesco divino entre as duas; no entanto, a música do seu Fausto é demoníaca, fruto do pacto com do Diabo. Vale lembrar que o mito fáustico surge também no período da Reforma, portanto, a relação entre Diabo e música é perfeitamente cabível. Já em A Montanha Mágica, a música figurava como "politicamente suspeita", pois representa "tudo o que existe de semi-articulado, de duvidoso, de irresponsável, de indiferente", induzindo "à complacência" e ao quietismo. ${ }^{37}$ Isso significa que a mais alemã de todas as artes, esconjuradora do tempo subjetivo, reflete nas relações interpessoais e na esfera política o mesmo isolacionismo oriundo da necessidade de interioridade extrema, que caracteriza o Protestantismo. O subjetivismo radical de um dos renovadores do Protestantismo, Kierkegaard, é também abordado por Mann:

Kierkegaard, a raiz do niilismo, é um dos temas do novo Fausto. $\mathrm{O}$ pensador dinamarquês considera o afastamento em face
37. MANN. A Montanha Mágica, p. 157.
EM TESE
BELO HORIZONTE
v. 21
N. 1
JAN.-ABR. 2015
SOUZA. A fortuna crítica de Thomas Mann № Brasil [...]
P. $116-129$

\section{Crítica Literária, outras Artes e Mídias}


38. ROSENFELD. Thomas Mann, p. 60.

39. ROSENFELD. Thomas Mann. do mundo como necessário, para que Deus possa irromper na pessoa. Mas este afastamento e alheamento leva, no caso de Adrian, justamente à irrupção do diabo ou já represente em si o elemento diabólico. ${ }^{38}$

Nesse sentido, Rosenfeld demonstra compreender de que modo as referências utilizadas por Mann são indispensáveis para desvendar os símbolos dessa obra que condena o individualismo fracassado tão enraizado na alma da Alemanha, quer seja pela música e tudo que nela há de suspeito, quer seja pelas raízes filosóficas plantadas nos tempos da Reforma. Por tanto querer afirmar o espírito, a interioridade, o Fausto de Mann não tem o corpo levado pelo Diabo, como o de Goethe, mas a própria alma. ${ }^{39}$

Após a sua análise brilhante de Doutor Fausto, que de certa forma lança luz para todas as outras obras, Rosenfeld conclui o ensaio retomando a relação intrínseca entre a vida e a obra de Thomas Mann, afirmando que, da dialética entre espírito e vida, esta triunfa, ainda que preservando a substância anímica - afinal, como disse Nietzsche pela boca de seu Zaratustra, espírito é apenas o nome de qualquer coisa do corpo. Reconhecer isso significa integrar o "pequeno mundo" do espírito no "grande mundo" da sociedade, tal como o faz o herói goethiano de Wilhelm Meister; ainda, é deixar a condição de outsider e inserir-se na mundanidade dos homens,

EM TESE
BELO HORIZONTE
N. 1
JAN.-ABR. 2015 como na lenda medieval de Parsifal. Isso sem falar do motivo do Fausto, que inquietou Lessing, Heine e Goethe. Segundo Rosenfeld, "vemos, portanto, que o motivo fundamental de Thomas Mann parece ser um motivo fundamental da literatura alemã". ${ }^{40}$ Mais do que isso: é o motivo fundamental da humanidade há mais de três milênios.

\section{CONSIDERAÇÕES FINAIS}

A obra de Thomas Mann foi o centro de diversas polêmicas no século XX, quer seja no plano político, quer seja no plano estético - embora essas duas esferas estejam em confluência em sua obra. Interessou-nos, no entanto, a maneira como a crítica literária lidou com isso. No final da década de 1940, Georg Lukács, em sua luta apaixonada contra as vanguardas literárias, considerou Thomas Mann como o escritor exemplar do realismo crítico. Theodor Adorno saiu em defesa das vanguardas, ainda que não se indispusesse com Mann, de quem era amigo. De qualquer forma, o juízo dos críticos vanguardistas era de que a sua obra padecia de um tradicionalismo pouco inventivo, estando deslocada do cenário artístico daquele período. No Brasil, o autor rendeu também admiradores e detratores: por exemplo, enquanto Anatol Rosenfeld escrevia ensaios exaltando a sua obra, Otto Maria Carpeaux condenava-a ao esquecimento. Foi justamente a apreciação dos dois críticos que compôs o nosso corpus de análise.
40. ROSENFELD. Thomas Mann, p.

\section{Crítica Literária, outras Artes e Midias}


Em um primeiro momento, observou-se na análise dos ensaios críticos de Otto Maria Carpeaux duas perspectivas sobre a obra de Thomas Mann. No ensaio "Admirável Thomas Mann”, Mann figura como um escritor de segunda ordem, sendo considerado tão decadente quanto a sua época; enquanto que nos textos de 1964 Carpeaux modifica o seu posicionamento, avaliando-o como um clássico do gênero romance. Já na análise dos dois ensaios de Anatol Rosenfeld, verificou-se um julgamento mais positivo, porquanto o crítico lança luz sobre Thomas Mann a partir de sua biografia, no entanto, sem se esquecer da própria obra, além de verificar como o autor de Doutor Fausto é fruto das contradições de seu tempo. Ademais, Rosenfeld analisa pormenorizadamente algumas das principais obras de Mann, destacando a sua unidade e evolução, ao passo de Carpeaux detém-se em considerações de cunho mais genérico, buscando desmascarar o autor e depois repará-lo. Em todo caso, se Rosenfeld mostrou-se mais atento e coerente em suas análises, Carpeaux, do mesmo modo que o próprio Mann fizera um Mea culpa com a publicação de $A$ Montanha Mágica, demonstra grandeza suficiente para mudar de opinião. Parafraseando o dito popular: o pior não é errar, é insistir no erro. Mas tanto a obra de Mann quanto a de Carpeaux justificam essa retratação.

\section{REFERÊNCIAS}

CARPEAUX, Otto Maria. Admirável Thomas Mann. In: Ensaios Reunidos: 1942-1978. Rio de Janeiro: UniverCidade Editora, 1999.

A Literatura Alemã. São Paulo: Cultrix, 1964a.

História da Literatura Ocidental: VI. Rio de Janeiro: O Cruzeiro, 1964b.

MANN, Thomas. A Gênese do Doutor Fausto: romance sobre um romance. Trad.: Ricardo F. Henrique. São Paulo: Mandarim, 2001

A Montanha Mágica. Trad.: Herbert Caro. Rio de Janeiro Nova Fronteira, 2006

Tonio Kroeger/ A Morte em Veneza. Trad.: Maria Deling São Paulo: Abril Cultural, 1971.

Ecce Homo. Trad.: Artur Morão. Covilhã: Lusosofia, 2008. (versão e-book).

ROSENFELD, Anatol. Thomas Mann. São Paulo: Perspectiva, 1994 